\title{
Description Is a Drag, and Vice Versa: Issues with Vocabulary Control
}

\author{
K.R. Roberto \\ Doctoral Student \\ University of Illinois at Urbana-Champaign \\ Graduate School of Library and Information Science \\ kroberto@illinois.edu
}

\begin{abstract}
How do controlled vocabularies address transgender topics? This talk explores the use of hierarchical taxonomic structures to describe people's often-fluid gender identities and sexuality, particularly the lack of accurate and appropriate language in most commonly used subject thes auri, and how the lack of this accurate and appropriate language can affect potential users. More specifically, this refers to individuals who identify as gendernonconforming. This term, as defined by the Sylvia Rivera Law Project, refers to "people who do not follow other people's ideas or stereotypes about how they should look or act based on the female or male sex they were as signed at birth." The phrase is frequently used as an umbrella term that encompasses a wide variety of gender identities, including transsexual, drag queen, genderqueer, and butch.

Many standard vocabularies have a long and complicated history with regards to prescriptive access points for marginalized groups and sexualities. This talk offers a historical overview of the ways in which authorized vocabularies have differed from vernacular language commonly used by community members and LGBTQ scholars to describe their own lives, and explores well- and les ser-known subject vocabularies such as the Library of Congress Subject Headings, Medical Subject Headings, terminology used by community archives and libraries, and tags assigned by LGBTQ people when describing their pers onal collections. The proposal builds on research by Melissa Adler, Sanford Berman, Ellen Greenblatt, Matt Johns on, Patrick Keilty, and Hope Ols on.
\end{abstract}

\section{REFERENCES}

This is the space reserved for copyright notices.

Advances in Classification Research, 2012, October 26, 2012, Baltimore, MD, USA.

Copyright notice continues right here.
Adler, M. (2009). Transcending library catalogs: A comparative study of controlled terms in Library of Congress subject headings and user-generated tags in LibraryThing for transgender books. Journal of Web Librarianship 3:4, pp. 309-331.

Berman, S. (1971). Prejudices andantipathies: A tract on the LC subject heads concerning people. Metuchen, N.J.: Scarecrow.

Greenblatt, E. (2011). The treatment of LGBTIQ subject concepts in the Library of Congress subject headings. In E. Greenblatt (Ed.), Serving LGBTIQ library and archives users: Essays on outreach, service, collections and access (pp. 212-228). Jefferson, N.C.: McFarland.

Johnson, M. (2010). Trans gender subject acces s: History and current practice. Cataloging \& Classification Quarterly 48:8, pp. 661-683.

Keilty, P. (2009). Tabulating queer: Space, perversion, and belonging. Knowledge Organization 36:4, pp. 240248.

Olson, H.A. (2000). Difference, culture and change: The untapped potential of LCSH. Cataloging \& Classification Quarterly 29(1/2), pp. 53-71. 